\title{
Bias in natriuretic peptide-guided heart failure trials: time to improve guideline adherence using alternative approaches
}

\author{
Susan Stienen ${ }^{1,2}$ (1) - Ankeet Bhatt ${ }^{3} \cdot$ João Pedro Ferreira ${ }^{1,4} \cdot$ Muthiah Vaduganathan $^{3} \cdot$ James Januzzi $^{5}$. \\ Kirkwood Adams $^{6}$ • Jean-Claude Tardif ${ }^{7} \cdot$ Patrick Rossignol $^{1} \cdot$ Faiez Zannad $^{1}$
}

Published online: 12 August 2020

(C) The Author(s) 2020

\begin{abstract}
Treatment of patients with heart failure with reduced ejection fraction (HFrEF) with currently available therapies reduces morbidity and mortality. However, implementation of these therapies is a problem with only few patients achieving guidelinerecommended maximal doses of therapy. In an effort to improve guideline adherence and uptitration, several trials have investigated a biomarker-guided strategy (using natriuretic peptide targets in specific), but although conceptually promising, these trials failed to show a consistent beneficial effect on outcomes. In this review, we discuss different methodological issues that may explain the failure of these trials and offer potential solutions. Moreover, alternative approaches to increase heart failure guideline adherence are evaluated.
\end{abstract}

Keywords HFrEF · Biomarker-guided trials · Biomarker · Natriuretic peptides · Guideline-directed · Medical therapy · Adherence $\cdot$ Bias

\section{Introduction}

Heart failure (HF) is a highly prevalent condition, with an incidence that continues to rise, driven largely by an improved survival of patients with atherosclerotic vascular disease, increasing rates of diabetes and obesity, and aging of the population [1]. Approximately $50 \%$ of patients with a documented history of HF have reduced ejection fraction (HFrEF), which is associated with a high risk of mortality and morbidity [2]. Large outcome trials have demonstrated that

Highlights

- Only few HFrEF patients achieve guideline-directed maximal doses of therapy

- Trials investigating a biomarker-guided strategy to titrate medication failed to show consistent effects on outcome

- Several methodological issues may explain the failure of these trials such as internal contamination bias

- Potential solutions are offered that may increase the use of guideline-directed therapy in heart failure patients

Susan Stienen

s.stienen@amc.uva.nl

1 INSERM, Centre d'Investigations Cliniques Plurithématique 1433, INSERM U1116, Université de Lorraine, CHRU de Nancy, F-CRIN INI-CRCT (Cardiovascular and Renal Clinical Trialists), Université de Lorraine, Nancy, France

2 Department of cardiology, Amsterdam University Medical Centers, Amsterdam, The Netherlands
3 Brigham and Women's Hospital, Boston, MA, USA

4 Department of Physiology and Cardiothoracic Surgery, Cardiovascular Research and Development Unit, Faculty of Medicine, University of Porto, Porto, Portugal

5 Massachusetts General Hospital, Boston, MA, USA

6 University of North Carolina, Chapel Hill, NC, USA

7 Montreal Heart Institute, Université de Montréal, Montréal, Canada 
pharmacologic treatments such as inhibitors of the reninangiotensin-aldosterone system (angiotensin-converting enzyme inhibitors (ACEi) and angiotensin receptor blockers (ARB) with or without neprilysin inhibitors), beta-adrenergic blockers (BBs) and mineralocorticoid receptor antagonists (MRAs) decrease mortality and hospitalizations rates in HFrEF [3]. However, in clinical practice, use of all of these three drug classes is uncommon and even fewer patients achieve guideline-recommended maximal doses of HF therapy $[4,5]$. Previous studies have shown that barriers to HF medication titration include patient-related factors (such as age, sex, body-mass index, renal function, comorbidities, and polypharmacy) but also physician-related (inexperience and knowledge gaps, fear of side effects, therapeutic inertia) and system-related factors (limited time and support structures to facilitate regular monitoring and transitions between hospital and general practitioner) [6-9]. In order to improve treatment adherence and uptitration, it has been hypothesized that a biomarker-targeted strategy could have a role in guiding intensification of guideline-directed medical therapy (GDMT).

\section{The rationale for biomarker-guided trials}

Similar to other therapeutic areas such as hyperlipidemia, type 2 diabetes mellitus, and obesity, measurement of circulating biomarkers has been proposed in an attempt to understand (1) residual risk and (2) response to therapy. For example, LDL cholesterol has been incorporated into guideline recommendations as a target to guide therapeutic efficacy and the need for therapeutic modification. In HF, many markers have been proposed, of which the natriuretic peptides (B-type natriuretic peptide (BNP) and N-terminal pro-BNP (NT-proBNP)) are the most extensively studied. Natriuretic peptides are indicators of ventricular wall stretch [10] and, to date, important parameters for diagnostic and prognostic purposes in HF [3]. Natriuretic peptides reflect congestion but also mirror other mechanisms of HF as can be appreciated by their reduction after initiation of several HF therapies [11]. Moreover, reductions in natriuretic peptides during both the acute and chronic phases of HF have been associated with an improved prognosis $[12,13]$. Hence, it was hypothesized that natriuretic peptides allow for an objective assessment of HF severity and may be used to "guide" the initiation and appropriate titration of HF therapies, potentially translating into improved clinical outcomes. As a result, several randomized controlled trials have been conducted in the past two decades assessing a natriuretic peptide-guided strategy and compared with standard of care [14-16]. Unfortunately, such strategies, while conceptually promising, have generally not shown a consistent improvement in outcomes.

\section{Why have natriuretic peptide-guided HF trials failed thus far?}

An overview of current natriuretic peptide-guided HF trials is listed in Table 1 . In 5 out of 14 trials, natriuretic peptideguided therapy reduced the rates of the primary endpoint compared to standard of care. These trials were all characterized by a significant titration of HF therapy in the natriuretic peptide-guided compared to the standard of care arm. Results from these trials suggest that HF therapies, when titrated to guideline recommended doses, lead to significantly lower natriuretic peptide levels and are associated with improved clinical outcomes. However, these positive trials have generally been limited by small sample sizes (ranging between 30 and 120 patients per treatment arm), which may lead to bias in the estimation of the treatment effect. For example, in the PROTECT trial [27], a sample size calculation based on an estimated relative risk reduction in total burden of cardiac events of $40 \%$ with NT-proBNP-guided treatment on top of standard of care was performed, while large trials comparing high- versus low-dose renin-angiotensin-aldosterone system (RAAS) inhibitors only demonstrated an $\sim 10 \%$ reduction in endpoints using a time-to-first-event analysis $[28,29]$. The largest trial thus far, the Guiding Evidence Based Therapy Using Biomarker Intensified Treatment in Heart Failure (GUIDE-IT), failed to demonstrate significant differences between patients randomized to NT-proBNP-guided therapy compared to standard of care in medication prescription rates and doses, change in NT-proBNP and the primary endpoint [15]. For this trial, a sample size calculation was performed based on a relative risk reduction of $20 \%$ in the primary endpoint (i.e., a composite of time-to-first HF hospitalization or cardiovascular mortality at 12 months).

Another potential hypothesis for the overall neutral results of the natriuretic peptide-guided trials has been that the majority of the study sites included in these trials had substantial expertise in HF care, possibly reducing between-group differences in HF therapy optimization. Also, it may be that patients were already very well treated at baseline in these specialized HF centers, making a significant change in HF treatment with a natriuretic peptide-guided strategy difficult and the treatment effect smaller. In order to substantiate this, we aimed to compare HF medication use in natriuretic peptide-guided trials versus usual care settings.

\section{Comparison of HF medication in natriuretic peptide-guided trials vs. usual care}

We reviewed the prescription rates and dosages of HF medication (ACEi or ARBs, BBs and MRAs) in 14 natriuretic peptide-guided trials and compared them to recent HF registries (CHECK-HF [4], CHAMP-HF [5], Swedish HF registry 


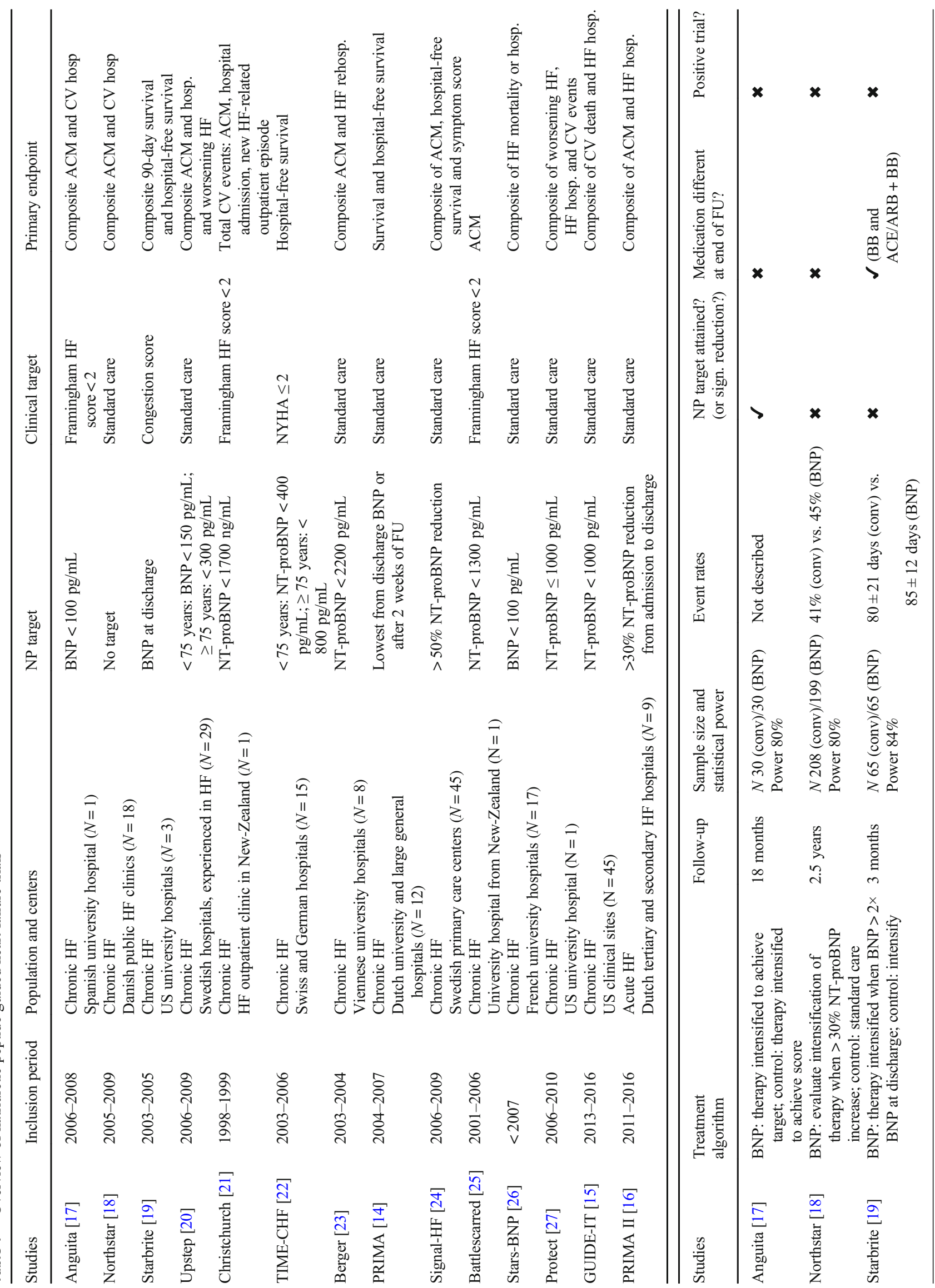




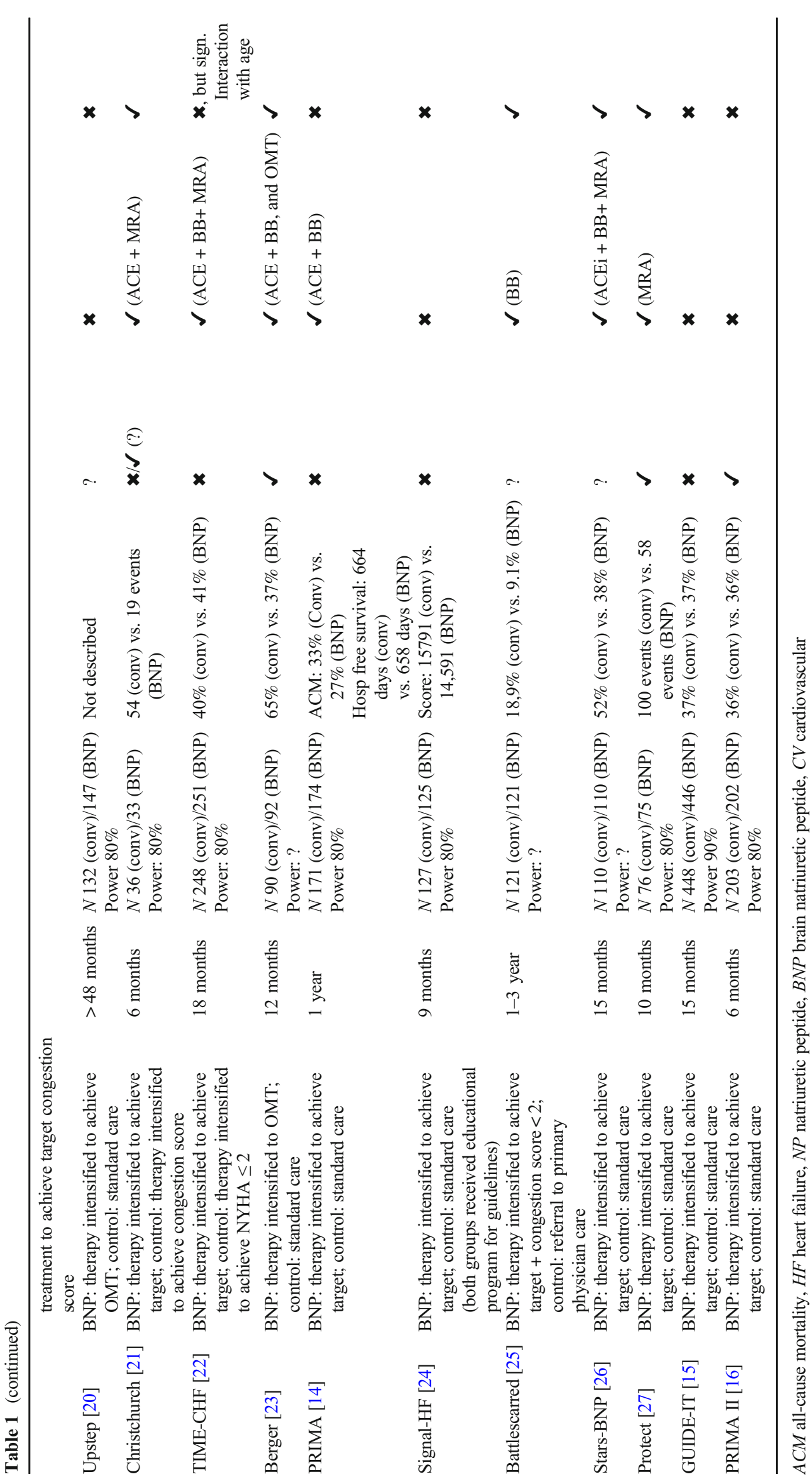


[9], QUALIFY [30], and ESC HF long term [31]). In addition, medication differences were studied between patients enrolled in large biomarker-guided randomized clinical trials based on their randomization assignment (natriuretic peptide-guided arm versus standard of care). Medication doses and treatment were compared at baseline and at the end of follow-up for each trial. Given the little evidence for disease modifying therapies in patients with $\mathrm{HF}$ and preserved ejection fraction, only patients with HFrEF were considered.

Prescription rates of ACEi/ARBs, BBs, and MRAs for all trials and registries are shown in Fig. 1a-c. Mean doses (as percentage of the maximum target dose as recommended by the ESC guidelines) [3] are shown in Fig. 2a-c. Prescription rates for ACEi/ARBs, BBs, and MRAs were low but similar between the natriuretic peptide-guided trials and recent HF registries. These data highlight the continued opportunity for improvement in GDMT implementation in patients with HF, and refute the notion that enrolled patients are already well treated for HF.

However, in natriuretic peptide-guided trials, HF medication was titrated to doses higher than those observed in a recent registry [4] irrespective of randomization to natriuretic peptide-guided therapy or standard of care (Fig. 2). These findings suggest that investigators in natriuretic peptideguided trials titrated HF medication to a similar extent in the natriuretic peptide-guided and the standard of care arms. But how do we reconcile these findings? A comparison of baseline characteristics of patients included in the trials and registries showed that patients generally have a similar age, distribution of sex, ischemic heart disease, systolic blood pressure and renal function (Table 2). Natriuretic peptide levels were slightly lower in the QUALIFY-HF [30] and ESC long-term HF registry [31] compared to the natriuretic peptide-guided trials, although patients within the Swedish HF registry [9] had similar natriuretic peptide levels as in the trials. This suggests that, in theory, differences in HF medication titration (and dosages) should not be present between the natriuretic peptide-guided trials and HF registries.
A potential explanation for the similar HF medication uptitration in both arms of the natriuretic peptide-guided trials may be internal contamination. In this setting, participating in a trial may result in a greater propensity of providers to actively uptitrate therapy. In addition, trial populations may capture a more engaged group of patients, and the infrastructure that exists at tertiary centers may allow for more structured followup to facilitate easy uptitration. In contrast, major registries enroll a usual care population with representation from of primary and secondary care centers, which may not have active programs for medication titration but are overall reflective of the HF population at large. The majority of centers participating in the biomarker-guided trials were indeed tertiary centers with specialized heart failure care programs (Table 1). Beyond this, intensity of follow-up related to greater than usual management might compound this hypothesis: in the GUIDE-IT HF trial, patients in the Usual Care arm of the trial were seen on average 10 times in a 15 -month period, far more than is typical in usual care settings. In total, those in the usual care arm in GUIDE-IT HF had comparable reduction in NT-proBNP compared to the biomarker-guided arm [32].

A summary of the potential reasons for failure of natriuretic peptide-guided trials is provided in Fig. 3.

\section{Alternative approaches to increase HF guideline adherence}

There are large opportunities to improve care of heart failure patients by optimizing GDMT. The challenge of providing high-quality, consistent, uptitration will require a unified approach that spans both the inpatient and outpatient settings. This will require the development of new trial strategies focused on implementation and engagement across the healthcare spectrum. Moreover, the efficacy of other biomarker (than natriuretic peptides) and non-biomarker approaches to increase uptitration of HF medication may be tested. We offer

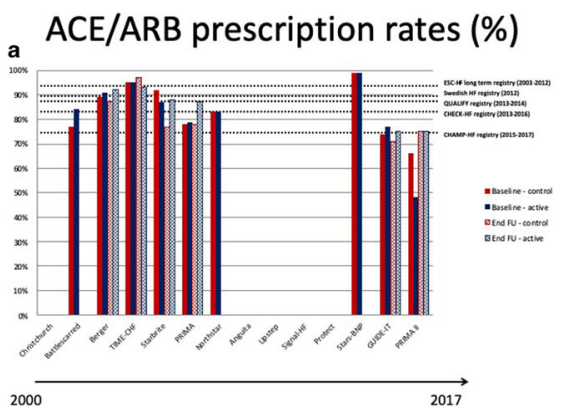

Fig. 1 Prescription rates of ACEi/ARBs (a), beta-blockers (b), and MRAs (c) in the different natriuretic-peptide guided-heart failure trials $\mathrm{at}$ baseline and end of follow-up according to treatment arm. In PRIMA
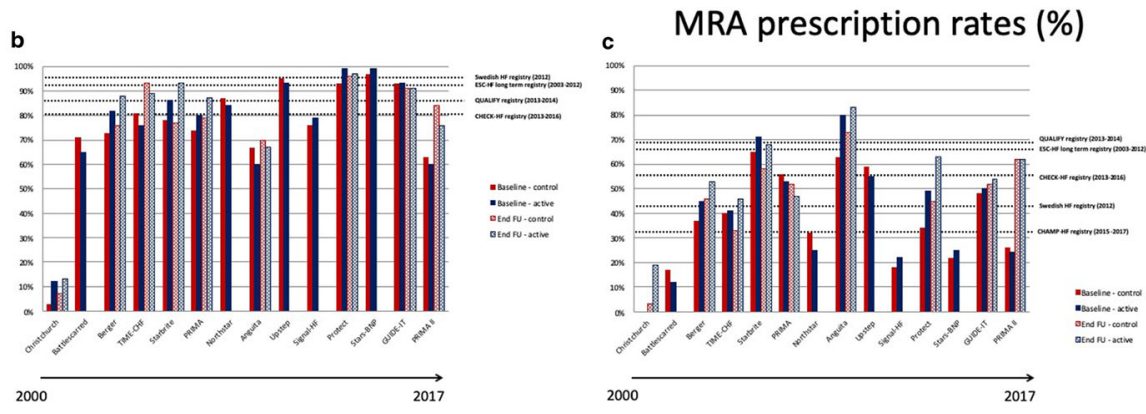

II, both new onset as chronic decompensated patients were included. Moreover, for these analyses, only patients with a left ventricular ejection fraction below $45 \%$ were selected 

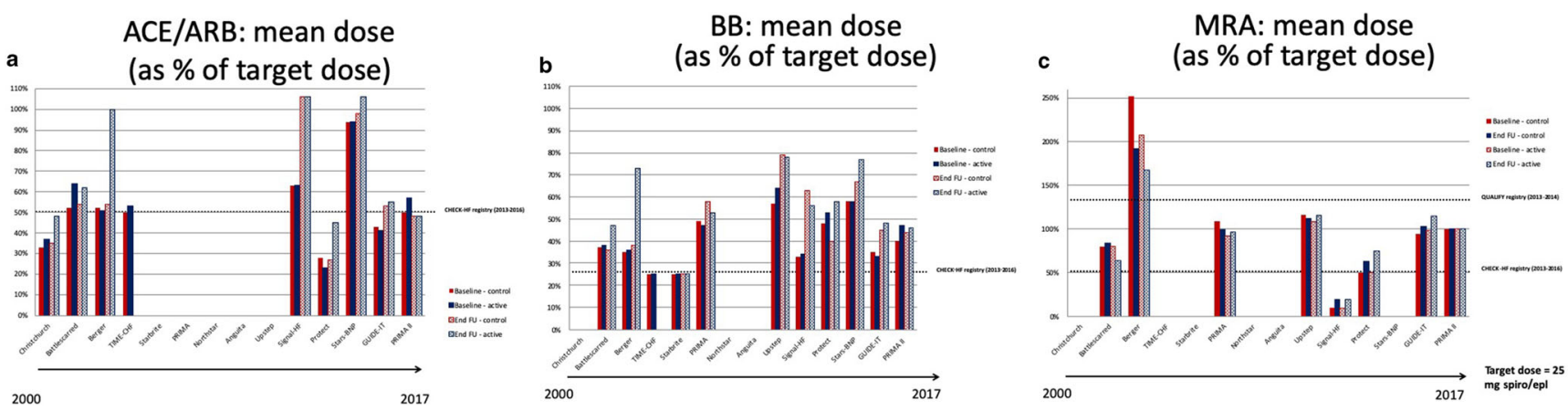

Fig. 2 Mean doses (as \% of target dose) of ACEi/ARBs (a), betablockers (b), and MRAs (c) in the different natriuretic-peptide guidedheart failure trials at baseline and end of follow-up according to treatment

some suggestions for the future design of guided GDMT trials in HF (Fig. 3).

\section{Cluster randomized natriuretic peptide-guided trials}

In general, blinding of the study procedure is performed in randomized controlled trials in an effort to minimize contamination. However, in cases where blinding is not possible or not preferred (such as with natriuretic peptide-guided HF treatment), cluster (or group) randomization may be considered. Here, a whole cluster (e.g., a hospital, geographical location, or a single physician) is assigned to a treatment or a control condition. In addition, a cluster design can also have practical advances over individual randomization in the form of lower costs and/or less challenging logistics. A disadvantage is however that a cluster randomized trial requires a larger sample size than a conventional randomized controlled trial as participants cannot be assumed to be independent because of the similarities within the same cluster, resulting in betweencluster variation and the need for adjustment [33].

\section{Other biomarker/hemodynamic-guided trials}

Natriuretic peptides are among the most strongly predictive markers for the diagnosis and prognosis of HF [3]. Suboptimal HF guideline adherence is probably not only due to inertia since this could be overcome by prompt signs of poor health (such as reflected by natriuretic peptides). Other explanations may be an inadequate assessment of residual decongestion and concerns about renal and potassium safety.

Pressure and impedance-based devices and/or biological biomarkers have the potential to identify patients with subclinical residual congestion who might potentially benefit from HF therapy optimization [34]. For example, the CardioMEMS Heart Sensor Allows Monitoring of Pressure to Improve Outcomes in New York Heart Association Class III Heart Failure Patients (CHAMPION) trial demonstrated that pulmonary artery pressure-guided management of chronic HF patients using a wireless implantable hemodynamic arm. In PRIMA II, both new onset as chronic decompensated patients were included. Moreover, for these analyses, only patients with a left ventricular ejection fraction below $45 \%$ were selected

monitoring system (CardioMEMS HF System, Abbott, Atlanta, GA) versus standard care significantly reduced HF hospitalizations [35]. While this trial focused on the appropriate management of subclinical congestion and not HF guideline adherence, we could envision a correlate trial with the use of a hemodynamic monitoring device in order to facilitate guideline medication uptitration. This may be a promising further area of study, particularly given angiotensin receptor neprilysin inhibitor therapy has overlapping natriuretic properties, and has been shown to reduce the need of high-dose diuretics [36].

Other promising, non-invasive, techniques are the measurement of lung impedance and lung ultrasonography to detect changes in lung fluid. Heart failure therapy guided by lung impedance measurements has been shown to significantly reduce HF hospitalization rates but again has currently been focused on monitoring subclinical congestion in order to augment diuretic therapy [37]. In a proof-of-concept study, lung ultrasound-guided diuretic treatment of pulmonary congestion also reduced the number of decompensations and improved walking capacity in patients with chronic HF [38].

A surrogate marker of congestion that has been proposed is estimated plasma volume (ePVS), calculated using hemoglobin and hematocrit [39]. Changes in ePVS were associated with cardiovascular endpoints in HF patients [39, 40]. Whether ePVS-guided treatment can improve outcome of HF patients has yet to be determined. Future areas of study may be to apply similar approaches to intensification of GDMT, as uptitration of therapy has been noted to reduce wall stress, improve left ventricular function, and perhaps reduced clinical congestion.

Overall, many of the biomarker and hemodynamic parameters have, to date, been used to detect early congestion and facilitate more aggressive diuresis. Evaluation of these markers and creating a guided strategy for medication uptitration may be useful. In addition, a more routine evaluation of, for example, iron status and QRS duration may lead to (earlier) identification of candidates for iron and cardiac resynchronization therapy respectively. Furthermore, the use 


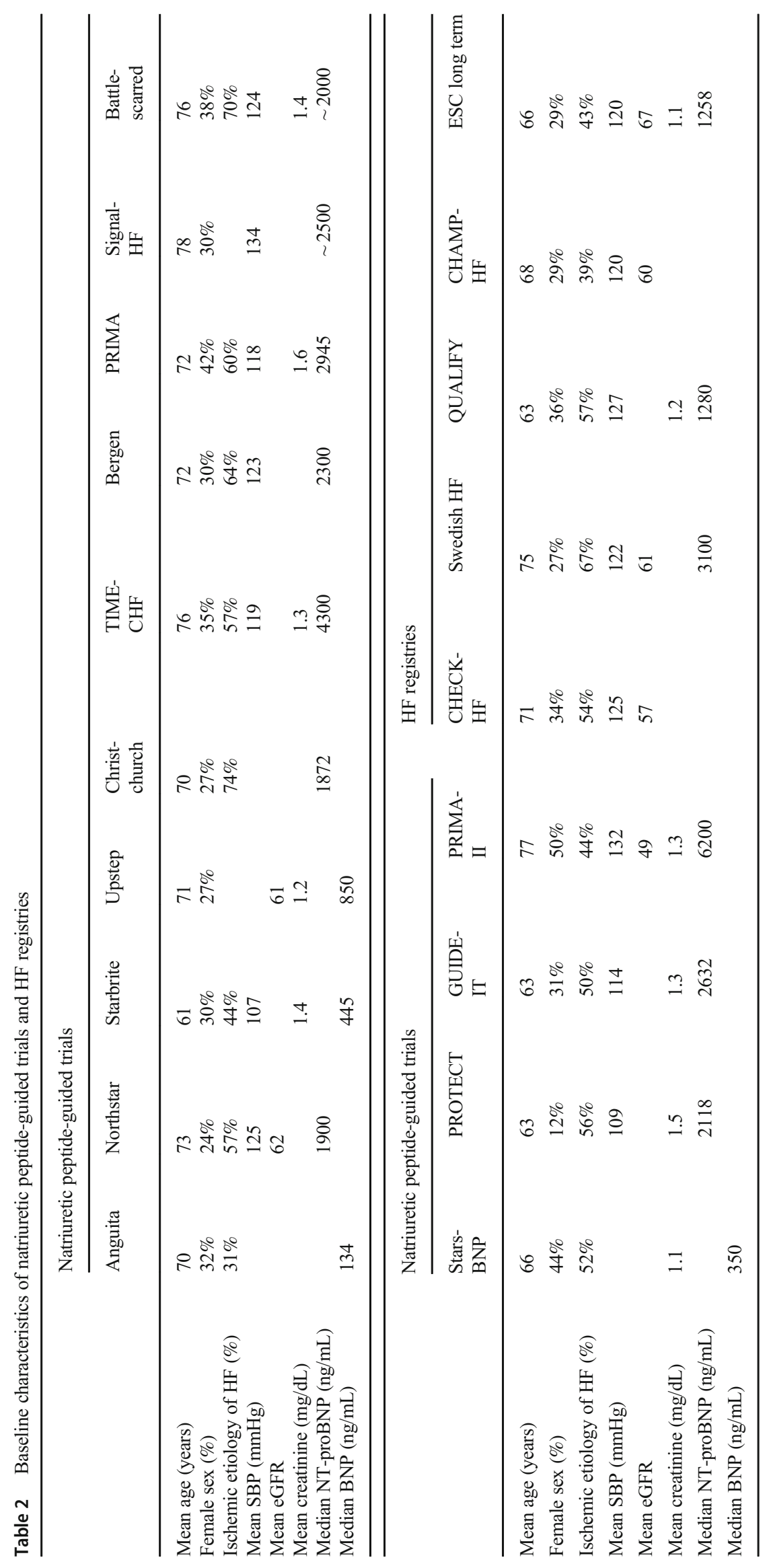




\section{NP-guided trials: why have they failed?}

POTENTIAL REASONS

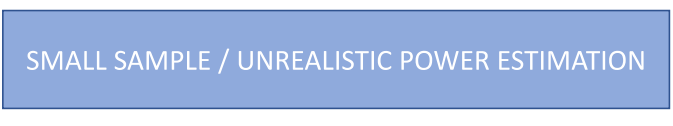

INTERNAL CONTAMINATION
POTENTIAL SOLUTIONS

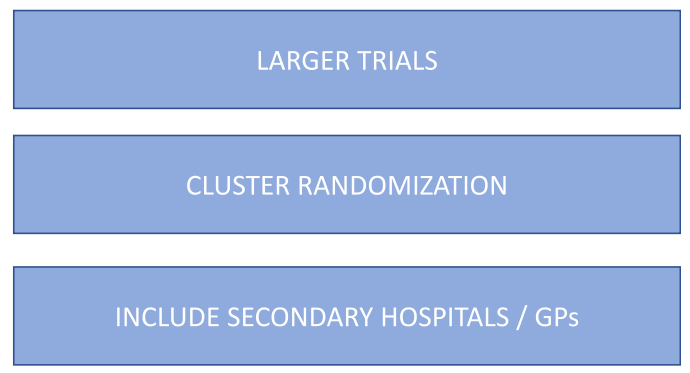

APPLY DIFFERENT STRATEGY (THAN NP-GUIDED)

1) PRESSURE AND IMPEDANCE-BASED DEVICES

2) DIFFERENT BIOMARKERS (OR COMBINED)

3) IMPLEMENTATION SCIENCE

Fig. 3 Failure of natriuretic peptide-guided trials: potential reasons and solutions to overcome them

of large data sets to define a "poly-biomarker" risk score may provide more utility then a single biomarker or the hemodynamic parameter alone. Such an approach would require the integration of biomarker data in conjunction with hemodynamic parameters in order to both identify patients at risk for decongestion, but also potentially identify opportunities for active uptitration in patients with continued residual heart failure risk. In an in silico analysis from BIOSTAT-CHF, a biomarker-based scenario (in which HF patients would have been uptitrated based on biomarker values) was favorable over a scenario in which all patients would have been successfully uptitrated to $>50 \%$ of recommended doses of ACEi/ARB, BB, and MRA [41]. Further study is needed to understand whether a poly-biomarker risk score guided approach may provide a framework for medication uptitration.

Numerous other markers have been identified as possible titration targets, including high-sensitivity troponin and soluble ST2 (STADE-HF (NCT02963272)). However, the impact of guided therapy using these biomarkers on the titration of HF therapy is probably limited since similar methodological (and practical) issues may be expected as were seen for natriuretic peptide-guided therapy.

\section{Implementation approaches}

A variety of non-biomarker approaches to increase HF guideline adherence have been assessed across multiple different settings. A recent observational study [42] using linked primary and secondary care data from general practices in the UK demonstrated that the median time from recorded HF symptoms to an actual HF diagnosis was 972 days (IQR 337-1468) and the time-to-treatment with HF-relevant medication 803 days (IQR 230-1364). It can be subsequently hypothesized that a program targeting an earlier recognition of HF could increase the uptake of guideline adherence, a concept that is currently under investigation [43]. In addition, educational efforts to improve HF therapy are being studied such as a "HF guideline training" for providers [44] or a combined approach at both the physician and patient level [45]. Inclusion of a multidisciplinary carrier team may be critical in facilitating uptitration, including nurse or pharmacist-led titration of HF medications [46, 47]. The concept of selfmonitoring and medication self-titration appeared feasible in high-risk hypertensive patients [48] and could potentially be employed in the heart failure setting perhaps utilizing mobile health technologies. Also, the development of GDMT clinics focusing on medication uptitration by highly specialized, well-experienced HF care providers has been suggested [49].

Another area of clear opportunity for therapy optimization is during or immediately following acute hospitalization for HF. It has been previously shown that in-hospital initiation of beta-blockers was safe in patients stabilized after HF admission, with no increased length of stay and with increased use 60 days after discharge compared with those patients without in-hospital initiation [50]. Also, recent data from PIONEERHF suggests that an in-hospital initiation strategy was safe in patients stabilized after acute HF and may result in important improvements in clinical outcomes at 8 weeks [51]. An intensive, protocol-driven titration of HF therapy after discharge is currently investigated in the "Safety, Tolerability and Efficacy of Rapid Optimization, Helped by NT-proBNP and GDF-15, of Heart Failure Therapies" (STRONG-HF; NCT03412201) study. Enhanced communication strategies to facilitate postdischarge care, including HF transition teams, may improve transitional communication and achievement of target doses of HF medication within 6 months of hospital discharge [52]. 
All of these efforts are worthwhile; however, the simplest approach would maybe be the development of an algorithm for the identification of patients at risk for not being uptitrated. This algorithm would subsequently create an automatic alert suggesting titration of HF medication. Targeting a high-risk population (i.e., patients after hospitalization for HF) could therefore be a cost-effective option. It is however possible that this population may be too sick to experience benefits from an intensified treatment approach. Moreover, the potential gain that can be achieved when medication adherence is improved across all HF patients should not be underestimated [53].

Excellent therapies are available for the treatment of HF with reduced ejection fraction but it is clear that patients do not receive the best treatment possible. Although several potential explanations can be put forward, we should no longer ignore our (partial) role in the undertreatment of our HF patients. Moreover, the recent discovery of, for example, SGLT2 inhibitors as novel therapeutic agents for HF has been groundbreaking but may unfortunately even further complicate routine clinical practice since this is yet another therapy that needs to be incorporated in a patients' treatment regimen.

There is a great need for a novel approach to improve HF care, possibly in the form of a dedicated multidisciplinary team having continuous access to telemedicine data including pointof-care biological measurements and pulmonary artery pressures. Moreover, the concept of natriuretic peptide-guided therapy cannot be dismissed before a cluster randomized trial is performed.

\section{Conclusions}

A careful review of literature led us to conclude that natriuretic peptide-guided trials were generally overoptimistic in the sample size estimation and subject to internal contamination bias, as can be observed by a similar titration of HF medication in the intervention and control groups and comparable reduction in NT-proBNP in the pivotal GUIDE-IT HF study. Potential solutions to overcome these issues are to perform a more realistic power calculation and a cluster randomization design. However, other promising approaches to improve HF guideline adherence exist such as pulmonary artery pressure and impedance-guided treatment and a variety of programs aiming at a better implementation of HF care. Further study is needed to identify a strategy enabling the use of GDMT in heart failure patients that is easy to implement in different clinical care settings worldwide.

\section{Compliance with ethical standards}

Conflict of interest The authors declare that they have no conflicts of interest.

Open Access This article is licensed under a Creative Commons Attribution 4.0 International License, which permits use, sharing, adaptation, distribution and reproduction in any medium or format, as long as you give appropriate credit to the original author(s) and the source, provide a link to the Creative Commons licence, and indicate if changes were made. The images or other third party material in this article are included in the article's Creative Commons licence, unless indicated otherwise in a credit line to the material. If material is not included in the article's Creative Commons licence and your intended use is not permitted by statutory regulation or exceeds the permitted use, you will need to obtain permission directly from the copyright holder. To view a copy of this licence, visit http://creativecommons.org/licenses/by/4.0/.

\section{References}

1. Benjamin EJ, Virani SS, Callaway CW, Chamberlain AM, Chang AR, Cheng S, Chiuve SE, Cushman M, Delling FN, Deo R, de Ferranti SD, Ferguson JF, Fornage M, Gillespie C, Isasi CR, Jiménez MC, Jordan LC, Judd SE, Lackland D, Lichtman JH, Lisabeth L, Liu S, Longenecker CT, Lutsey PL, Mackey JS, Matchar DB, Matsushita K, Mussolino ME, Nasir K, O'Flaherty M, Palaniappan LP, Pandey A, Pandey DK, Reeves MJ, Ritchey MD, Rodriguez CJ, Roth GA, Rosamond WD, Sampson UKA, Satou GM, Shah SH, Spartano NL, Tirschwell DL, Tsao CW, Voeks JH, Willey JZ, Wilkins JT, Wu JH, Alger HM, Wong SS, Muntner P, American Heart Association Council on Epidemiology and Prevention Statistics Committee and Stroke Statistics Subcommittee (2018) Heart disease and stroke statistics-2018 update: a report from the American Heart Association. Circulation. 137(12):e67-e492

2. Bui AL, Horwich TB, Fonarow GC (2011) Epidemiology and risk profile of heart failure. Nat Rev Cardiol 8(1):30-41

3. Ponikowski P, Voors AA, Anker SD, Bueno H, Cleland JGF, Coats AJS et al (2016) 2016 ESC guidelines for the diagnosis and treatment of acute and chronic heart failure: the Task Force for the diagnosis and treatment of acute and chronic heart failure of the European Society of Cardiology (ESC). Developed with the special contribution of the Heart Failure Association (HFA) of the ESC. Eur Heart J 37(27):2129-2200

4. Brunner-La Rocca HP, Linssen GC, Smeele FJ, van Drimmelen AA, Schaafsma HJ, Westendorp PH et al (2019) Contemporary drug treatment of chronic heart failure with reduced ejection fraction: the CHECK-HF registry. JACC Heart Fail 7(1):13-21

5. Peri-Okonny PA, Mi X, Khariton Y, Patel KK, Thomas L, Fonarow GC et al (2019) Target doses of heart failure medical therapy and blood pressure: insights from the CHAMP-HF Registry. JACC Heart Fail 7(4):350-358

6. Carroll R, Mudge A, Suna J, Denaro C, Atherton J (2016) Prescribing and up-titration in recently hospitalized heart failure patients attending a disease management program. Int $\mathrm{J}$ Cardiol 216:121-127

7. Dev S, Hoffman TK, Kavalieratos D, Heidenreich P, Wu WC, Schwenke DC, Tracy SJ (2016) Barriers to adoption of mineralocorticoid receptor antagonists in patients with heart failure: a mixed-methods study. J Am Heart Assoc 5(3):e002493

8. Gustafsson F, Schou M, Videbaek L, Nielsen T, Ulriksen H, Markenvard J, Svendsen TL, Ryde H, Vigholt E, Hildebrandt P, on behalf of the Danish Heart Failure Clinics Network (2007) Treatment with beta-blockers in nurse-led heart failure clinics: titration efficacy and predictors of failure. Eur J Heart Fail 9(9):910 916

9. Savarese G, Carrero JJ, Pitt B, Anker SD, Rosano GMC, Dahlstrom $\mathrm{U}$ et al (2018) Factors associated with underuse of mineralocorticoid receptor antagonists in heart failure with reduced ejection 
fraction: an analysis of 11215 patients from the Swedish Heart Failure Registry. Eur J Heart Fail 20(9):1326-1334

10. Kinnunen P, Vuolteenaho O, Ruskoaho H (1993) Mechanisms of atrial and brain natriuretic peptide release from rat ventricular myocardium: effect of stretching. Endocrinology. 132(5):1961-1970

11. Rosenberg J, Gustafsson F, Remme WJ, Riegger GA, Hildebrandt PR (2008) Effect of beta-blockade and ACE inhibition on B-type natriuretic peptides in stable patients with systolic heart failure. Cardiovasc Drugs Ther 22(4):305-311

12. Masson S, Latini R, Anand IS, Barlera S, Angelici L, Vago T, Tognoni G, Cohn JN, Val-HeFT Investigators (2008) Prognostic value of changes in $\mathrm{N}$-terminal pro-brain natriuretic peptide in ValHeFT (Valsartan Heart Failure Trial). J Am Coll Cardiol 52(12): 997-1003

13. Salah K, Kok WE, Eurlings LW, Bettencourt P, Pimenta JM, Metra M, Bayes-Genis A, Verdiani V, Bettari L, Lazzarini V, Damman P, Tijssen JG, Pinto YM (2014) A novel discharge risk model for patients hospitalised for acute decompensated heart failure incorporating N-terminal pro-B-type natriuretic peptide levels: a European coLlaboration on Acute decompeNsated Heart Failure: ELAN-HF Score. Heart 100(2):115-125

14. Eurlings LW, van Pol PE, Kok WE, van Wijk S, Lodewijks-van der Bolt C, Balk AH et al (2010) Management of chronic heart failure guided by individual N-terminal pro-B-type natriuretic peptide targets: results of the PRIMA (Can PRo-brain-natriuretic peptide guided therapy of chronic heart failure IMprove heart fAilure morbidity and mortality?) study. J Am Coll Cardiol 56(25):2090-2100

15. Felker GM, Anstrom KJ, Adams KF, Ezekowitz JA, Fiuzat M, Houston-Miller N, Januzzi JL Jr, Mark DB, Piña IL, Passmore G, Whellan DJ, Yang H, Cooper LS, Leifer ES, Desvigne-Nickens P, O'Connor CM (2017) Effect of natriuretic peptide-guided therapy on hospitalization or cardiovascular mortality in high-risk patients with heart failure and reduced ejection fraction: a randomized clinical trial. Jama. 318(8):713-720

16. Stienen S, Salah K, Moons AH, Bakx AL, van Pol P, Kortz RAM, Ferreira JP, Marques I, Schroeder-Tanka JM, Keijer JT, BayésGenis A, Tijssen JGP, Pinto YM, Kok WE (2018) NT-proBNP (N-terminal pro-B-type natriuretic peptide)-guided therapy in acute decompensated heart failure: PRIMA II randomized controlled trial (Can NT-ProBNP-guided therapy during hospital admission for acute decompensated heart failure reduce mortality and readmissions?). Circulation. 137(16):1671-1683

17. Anguita M, Esteban F, Castillo JC, Mazuelos F, Lopez-Granados A, Arizon JM et al (2010) Usefulness of brain natriuretic peptide levels, as compared with usual clinical control, for the treatment monitoring of patients with heart failure. Med Clin 135(10):435440

18. Schou M, Gustafsson F, Videbaek L, Andersen H, Toft J, Nyvad O, Ryde H, Fog L, Jensen JCH, Nielsen OW, Lind-Rasmussen S, Abdulla J, Hildebrandt PR, on behalf of the NorthStar Investigators, All members of the Danish Heart Failure Clinics Network (2013) Adding serial N-terminal pro brain natriuretic peptide measurements to optimal clinical management in outpatients with systolic heart failure: a multicentre randomized clinical trial (NorthStar monitoring study). Eur J Heart Fail 15(7):818-827

19. Shah MR, Califf RM, Nohria A, Bhapkar M, Bowers M, Mancini DM, Fiuzat M, Stevenson LW, O'Connor CM (2011) The STARBRITE trial: a randomized, pilot study of B-type natriuretic peptide-guided therapy in patients with advanced heart failure. $\mathrm{J}$ Card Fail 17(8):613-621

20. Karlstrom P, Alehagen U, Boman K, Dahlstrom U (2011) Brain natriuretic peptide-guided treatment does not improve morbidity and mortality in extensively treated patients with chronic heart failure: responders to treatment have a significantly better outcome. Eur J Heart Fail 13(10):1096-1103
21. Troughton RW, Frampton CM, Yandle TG, Espiner EA, Nicholls MG, Richards AM (2000) Treatment of heart failure guided by plasma aminoterminal brain natriuretic peptide $(\mathrm{N}-\mathrm{BNP})$ concentrations. Lancet. 355(9210):1126-1130

22. Pfisterer M, Buser P, Rickli H, Gutmann M, Erne P, Rickenbacher P, Vuillomenet A, Jeker U, Dubach P, Beer H, Yoon SI, Suter T, Osterhues HH, Schieber MM, Hilti P, Schindler R, Brunner-la Rocca HP, TIME-CHF Investigators (2009) BNP-guided vs symptom-guided heart failure therapy: the Trial of Intensified vs Standard Medical Therapy in Elderly Patients With Congestive Heart Failure (TIME-CHF) randomized trial. Jama. 301(4):383392

23. Berger R, Moertl D, Peter S, Ahmadi R, Huelsmann M, Yamuti S, Wagner B, Pacher R (2010) N-terminal pro-B-type natriuretic peptide-guided, intensive patient management in addition to multidisciplinary care in chronic heart failure a 3-arm, prospective, randomized pilot study. J Am Coll Cardiol 55(7):645-653

24. Persson H, Erntell H, Eriksson B, Johansson G, Swedberg K, Dahlstrom U (2010) Improved pharmacological therapy of chronic heart failure in primary care: a randomized Study of NT-proBNP Guided Management of Heart Failure-SIGNAL-HF (Swedish Intervention study-guidelines and NT-proBNP AnaLysis in Heart Failure). Eur J Heart Fail 12(12):1300-1308

25. Lainchbury JG, Troughton RW, Strangman KM, Frampton CM, Pilbrow A, Yandle TG, Hamid AK, Nicholls MG, Richards AM (2009) N-terminal pro-B-type natriuretic peptide-guided treatment for chronic heart failure: results from the BATTLESCARRED (NT-proBNP-Assisted Treatment To Lessen Serial Cardiac Readmissions and Death) trial. J Am Coll Cardiol 55(1):53-60

26. Jourdain P, Jondeau G, Funck F, Gueffet P, Le Helloco A, Donal E et al (2007) Plasma brain natriuretic peptide-guided therapy to improve outcome in heart failure: the STARS-BNP Multicenter Study. J Am Coll Cardiol 49(16):1733-1739

27. Januzzi JL Jr, Rehman SU, Mohammed AA, Bhardwaj A, Barajas L, Barajas J, Kim HN, Baggish AL, Weiner RB, Chen-Tournoux A, Marshall JE, Moore SA, Carlson WD, Lewis GD, Shin J, Sullivan D, Parks K, Wang TJ, Gregory SA, Uthamalingam S, Semigran MJ (2011) Use of amino-terminal pro-B-type natriuretic peptide to guide outpatient therapy of patients with chronic left ventricular systolic dysfunction. J Am Coll Cardiol 58(18):1881-1889

28. Claggett B, Packer M, McMurray JJ, Swedberg K, Rouleau J, Zile MR, Jhund P, Lefkowitz M, Shi V, Solomon SD, PARADIGM-HF Investigators (2015) Estimating the long-term treatment benefits of sacubitril-valsartan. N Engl J Med 373(23):2289-2290

29. Konstam MA, Neaton JD, Dickstein K, Drexler H, Komajda M, Martinez FA, Riegger GAJ, Malbecq W, Smith RD, Guptha S, Poole-Wilson PA (2009) Effects of high-dose versus low-dose losartan on clinical outcomes in patients with heart failure (HEAAL study): a randomised, double-blind trial. Lancet. 374(9704):1840-1848

30. Komajda M, Cowie MR, Tavazzi L, Ponikowski P, Anker SD, Filippatos GS, on behalf of the QUALIFY Investigators (2017) Physicians' guideline adherence is associated with better prognosis in outpatients with heart failure with reduced ejection fraction: the QUALIFY international registry. Eur J Heart Fail 19(11):14141423

31. Crespo-Leiro MG, Anker SD, Maggioni AP, Coats AJ, Filippatos G, Ruschitzka F, Ferrari R, Piepoli MF, Delgado Jimenez JF, Metra M, Fonseca C, Hradec J, Amir O, Logeart D, Dahlström U, Merkely B, Drozdz J, Goncalvesova E, Hassanein M, Chioncel O, Lainscak M, Seferovic PM, Tousoulis D, Kavoliuniene A, Fruhwald F, Fazlibegovic E, Temizhan A, Gatzov P, Erglis A, Laroche C, Mebazaa A, on behalf of the Heart Failure Association (HFA) of the European Society of Cardiology (ESC) (2016) European Society of Cardiology Heart Failure Long-Term 
Registry (ESC-HF-LT): 1-year follow-up outcomes and differences across regions. Eur J Heart Fail 18(6):613-625

32. Januzzi JL, Ahmad T, Mulder H, Coles A, Anstrom KJ, Adams KF et al (2019) Natriuretic peptide response and outcomes in chronic heart failure with reduced ejection fraction. J Am Coll Cardiol 74(9):1205-1217

33. Fiero MH, Huang S, Oren E, Bell ML (2016) Statistical analysis and handling of missing data in cluster randomized trials: a systematic review. Trials. 17:72

34. Girerd N, Seronde MF, Coiro S, Chouihed T, Bilbault P, Braun F, Kenizou D, Maillier B, Nazeyrollas P, Roul G, Fillieux L, Abraham WT, Januzzi J Jr, Sebbag L, Zannad F, Mebazaa A, Rossignol P, INI-CRCT, Great Network, and the EF-HF Group (2018) Integrative assessment of congestion in heart failure throughout the patient journey. JACC Heart Fail 6(4):273-285

35. Givertz MM, Stevenson LW, Costanzo MR, Bourge RC, Bauman JG, Ginn G, Abraham WT, CHAMPION Trial Investigators (2017) Pulmonary artery pressure-guided management of patients with Heart failure and reduced ejection fraction. J Am Coll Cardiol 70(15): $1875-1886$

36. Vardeny O, Claggett B, Kachadourian J, Desai AS, Packer M, Rouleau J, Zile MR, Swedberg K, Lefkowitz M, Shi V, McMurray JJV, Solomon SD (2019) Reduced loop diuretic use in patients taking sacubitril/valsartan compared with enalapril: the PARADIGM-HF trial. Eur J Heart Fail 21(3):337-341

37. Shochat MK, Shotan A, Blondheim DS, Kazatsker M, Dahan I, Asif A, Rozenman Y, Kleiner I, Weinstein JM, Frimerman A, Vasilenko L, Meisel SR (2016) Non-invasive lung IMPEDANCE-guided preemptive treatment in chronic heart failure patients: a randomized controlled trial (IMPEDANCE-HF trial). J Card Fail 22(9):713-722

38. Rivas-Lasarte M, Álvarez-García J, Fernández-Martínez J, Maestro A, López-López L, Solé-González E, Pirla MJ, Mesado N, Mirabet S, Fluvià P, Brossa V, Sionis A, Roig E, Cinca J (2019) Lung ultrasound-guided treatment in ambulatory patients with heart failure: a randomized controlled clinical trial (LUS-HF study). Eur $\mathbf{J}$ Heart Fail 21(12):1605-1613

39. Duarte K, Monnez JM, Albuisson E, Pitt B, Zannad F, Rossignol P (2015) Prognostic value of estimated plasma volume in heart failure. JACC Heart Fail 3(11):886-893

40. Kobayashi M, Rossignol P, Ferreira JP, Aragao I, Paku Y, Iwasaki $Y$ et al (2018) Prognostic value of estimated plasma volume in acute heart failure in three cohort studies. Clin Res Cardiol 108(5):549561

41. Ouwerkerk W, Zwinderman AH, Ng LL, Demissei B, Hillege HL, Zannad F, van Veldhuisen DJ, Samani NJ, Ponikowski P, Metra M, ter Maaten JM, Lang CC, van der Harst P, Filippatos G, Dickstein K, Cleland JG, Anker SD, Voors AA (2018) Biomarker-guided versus guideline-based treatment of patients with heart failure: results from BIOSTAT-CHF. J Am Coll Cardiol 71(4):386-398

42. Hayhoe B, Kim D, Aylin PP, Majeed FA, Cowie MR, Bottle A (2018) Adherence to guidelines in management of symptoms suggestive of heart failure in primary care. Heart 105(9):678-685

43. van Riet EE, Hoes AW, Limburg A, van der Hoeven H, Landman MA, Rutten FH (2014) Strategy to recognize and initiate treatment of chronic heart failure in primary care (STRETCH): a cluster randomized trial. BMC Cardiovasc Disord 14:1

44. Valk MJ, Hoes AW, Mosterd A, Landman MA, Broekhuizen BD, Rutten FH (2015) Rationale, design and baseline results of the Treatment Optimisation in Primary care of Heart failure in the Utrecht region (TOPHU) study: a cluster randomised controlled trial. BMC Fam Pract 16:130

45. Mangla A, Doukky R, Richardson D, Avery EF, Dawar R, Calvin JE Jr, Powell LH (2018) Design of a bilevel clinical trial targeting adherence in heart failure patients and their providers: the Congestive Heart Failure Adherence Redesign Trial (CHART). Am Heart J 195:139-150

46. Driscoll A, Currey J, Tonkin A, Krum H (2015) Nurse-led titration of angiotensin converting enzyme inhibitors, beta-adrenergic blocking agents, and angiotensin receptor blockers for people with heart failure with reduced ejection fraction. Cochrane Database Syst Rev 21(12):Cd009889

47. Gattis WA, Hasselblad V, Whellan DJ, O'Connor CM (1999) Reduction in heart failure events by the addition of a clinical pharmacist to the heart failure management team: results of the Pharmacist in Heart Failure Assessment Recommendation and Monitoring (PHARM) study. Arch Intern Med 159(16):1939-1945

48. McManus RJ, Mant J, Haque MS, Bray EP, Bryan S, Greenfield SM, Jones MI, Jowett S, Little P, Penaloza C, Schwartz C, Shackleford H, Shovelton C, Varghese J, Williams B, Hobbs FD, Gooding T, Morrey I, Fisher C, Buckley D (2014) Effect of selfmonitoring and medication self-titration on systolic blood pressure in hypertensive patients at high risk of cardiovascular disease: the TASMIN-SR randomized clinical trial. Jama. 312(8):799-808

49. O'Connor CM (2019) Guideline-directed medical therapy clinics: a call to action for the heart failure team. JACC Heart Fail 7(5):442443

50. Gattis WA, O'Connor CM, Gallup DS, Hasselblad V, Gheorghiade M (2004) Coordinators I-HIa. Predischarge initiation of carvedilol in patients hospitalized for decompensated heart failure: results of the Initiation Management Predischarge: Process for Assessment of Carvedilol Therapy in Heart Failure (IMPACT-HF) trial. J Am Coll Cardiol 43(9): 1534-1541

51. Morrow DA, Velazquez EJ, DeVore AD, Desai AS, Duffy CI, Ambrosy AP et al (2019) Clinical outcomes in patients with acute decompensated heart failure randomly assigned to sacubitril/ valsartan or enalapril in the PIONEER-HF trial. Circulation. 139(19):2285-2288

52. Hickey A, Suna J, Marquart L, Denaro C, Javorsky G, Munns A, Mudge A, Atherton JJ (2016) Improving medication titration in heart failure by embedding a structured medication titration plan. Int J Cardiol 224:99-106

53. Fonarow GC, Yancy CW, Hernandez AF, Peterson ED, Spertus JA, Heidenreich PA (2011) Potential impact of optimal implementation of evidence-based heart failure therapies on mortality. Am Heart $\mathrm{J}$ 161(6):1024-30.e3

Publisher's note Springer Nature remains neutral with regard to jurisdictional claims in published maps and institutional affiliations. 